\title{
GCU
}

Glasgow Caledonian

University

University for the Common Good

\section{Self-regulated learning in the workplace: strategies and factors in the attainment of learning goals}

Margaryan, Anoush; Littlejohn, Allison; Milligan, Colin

Published in:

International Journal of Training and Development

DOI:

10.1111/ijtd.12013

Publication date:

2013

Document Version

Author accepted manuscript

Link to publication in ResearchOnline

Citation for published version (Harvard):

Margaryan, A, Littlejohn, A \& Milligan, C 2013, 'Self-regulated learning in the workplace: strategies and factors in the attainment of learning goals', International Journal of Training and Development, vol. 17, no. 4, pp. 245-259. https://doi.org/10.1111/ijtd.12013

\section{General rights}

Copyright and moral rights for the publications made accessible in the public portal are retained by the authors and/or other copyright owners and it is a condition of accessing publications that users recognise and abide by the legal requirements associated with these rights.

Take down policy

If you believe that this document breaches copyright please view our takedown policy at https://edshare.gcu.ac.uk/id/eprint/5179 for details of how to contact us. 


\title{
Self-regulated learning in the workplace: strategies and factors in the attainment of learning goals
}

\author{
Anoush Margaryan*, Allison Littlejohn, and Colin Milligan \\ Caledonian Academy, Glasgow Caledonian University, UK \\ * Corresponding Author: anoush.margaryan@gcu.ac.uk
}

\begin{abstract}
The paper identifies professionals' self-regulatory strategies underpinning planning and attainment of learning goals in the workplace, surfacing a number of organisational factors impacting these. Data are based on semi-structured interviews $(n=29)$. Findings indicate that self-regulatory learning practices in the workplace are iterative and fluid rather than delineated into discrete stages as suggested by phase models of self-regulation. There is little deliberate, systematic selfreflection on learning in the workplace. Learning goals are driven by short-term work tasks and individuals' longer-term development needs. Professionals draw extensively upon supervisors, mentors and colleagues when planning and attaining their learning goals. Formation of learning goals is constrained by individuals' perceptions of their career development potential and of how their progression potential is viewed by the organisation in which they work. Similarities and differences in the perceptions of experienced, novice and mid-career professionals of these strategies and factors are analysed.
\end{abstract}




\section{Introduction}

This paper describes the findings of an exploratory, qualitative study, examining how professionals self-regulate their learning in the workplace. What do we mean by 'learning in the workplace' and by 'self-regulation of learning'? The literature on continuing professional development (CPD) and workplace learning (WPL) describe various forms of learning that professionals may engage in formal and informal, structured and non-structured, on-the-job or off-the-job (Colley, Hodkinson and Malcolm, 2002; Collin, van der Heijden, and Lewis, 2012). Our interest in this paper specifically is on informal, on-the-job learning that takes place through participation in everyday work, individually or in collaboration with others (Billet, Harteis, and Etelaepelto, 2008; Eraut, 2004). Sometimes this learning may be structured and planned (personal development planning, coaching and mentoring, project meetings or after-action reviews). At other times it may be unstructured and incidental (for instance, when seeking help through personal contacts or spontaneous knowledge exchanges with others). Such learning incorporates a range of workplace activities and practices which 'generate learning without learning being an express objective' (Collin et al, 2012, p. 155). Workplace activities, guided by work-based goals, with learning as a by-product, are rarely acknowledged as learning activities, because they are a normal part of everyday working life (Eraut, 2007). Nevertheless, recent studies have evidenced that deep and powerful learning occurs through everyday work (Billett, 2010; Felstead, Fuller, Jewson, and Unwin, 2009; Stenstroem and Tynjala, 2009).

Self-regulation of learning refers to "...self-generated thoughts, feelings and actions that are planned and cyclically adapted to the attainment of personal goals" (Zimmerman, 2005, p. 14). In particular, our analysis focuses on professionals' self-regulatory actions related to planning and attainment of learning goals and to factors impacting the formation of these goals.

As the nature of work evolves, understanding how professionals self-regulate their learning in the context of everyday work becomes increasingly important (Bateman and Barry, 2012; Lord, Diefendorff, Schmidt and Hall, 2010; Sitzmann and Ely, 2011). Informal learning at work is recognised as a key component in continuing professional development (Cheetham and Chivers, 2001). Informal learning has been gaining in prominence as increasingly specialised, distributed and changing work practices require professionals to solve novel problems, identify what they need to know and recognise where they can obtain the necessary information or how they may create new knowledge (Littlejohn, Milligan, and Margaryan, 2012; Margaryan, 2008). In contrast to formal learning settings where learning goals and pathways to achieving these are explicitly defined, in informal, workplace learning contexts professionals have to engage in self-regulation to articulate and pursue their learning goals. The ability to self-regulate one's own learning through goal setting, self-monitoring, self-reflection and adaptation is a central component of expertise development in any domain (Ericsson, 2006; Zimmerman, 2006) and research has shown that self-regulation is a predictive factor for work-related learning behaviour (Gijbels, Raemdonck, Vervecken, and van Herck, 2012). Therefore, understanding how self-regulation develops and exhibits itself in the workplace is an important task in theorising workplace learning.

Self-regulated learning (SRL) is a broad domain. A recent meta-analysis examining the current state of research on self-regulated learning identified seven different theories and sixteen different, fundamental constructs of self-regulation, emerging from different disciplines including educational, organisational and clinical psychology, and cybernetics (Sitzmann and Ely, 2011). The main theories of self-regulation reviewed by Siztmann and Ely include control theory, goal setting theory, action regulation theory, resource allocation theory, self-efficacy theory as well as phase models of self-regulation. The key constructs comprising self-regulation include goals, planning, monitoring, learning strategies, help seeking, and self-evaluation, among others (Sitzmann et al, 2011). While the former theories have been applied predominantly to explain self-regulation of behaviour and performance more generally, the phase models - in particular, Zimmerman's threephase model (Zimmerman, 2005) and Pintrich's four-phase model (Pintrich, 2000) - have been especially influential in the analysis of learning. While these theories have a divergent background, 
they share commonalities, the most important of which is the postulate that self-regulation is triggered by goal-setting. Both organisational and educational psychology literatures examining the mechanisms underpinning self-regulation posit that human behaviour is goal-directed: all humans self-regulate their own functioning - their behaviour, their cognition and their emotions in order to attain goals in life (Carver and Scheier, 2005; Zimmerman, 2005). Goals are defined as representations of desired states (Austin and Vancouver, 1996). The function of goals is to direct attention toward the activity at hand, stimulating increased effort and persistence, as well as discovery and use of strategies and knowledge necessary to complete the activity (Sitzmann et al, 2011). Goals define standards for successfully accomplishing a task and provide a criterion for planning, strategy selection, monitoring, evaluation and other processes underpinning selfregulation (Hadwin et al, 2011; Sitzmann and Ely, 2011). Because of the central role that goals play in initiating self-regulation, the analysis of the factors impacting the formation of learning goals at work is essential in developing our understanding of self-regulatory learning processes in the workplace.

Despite a sizeable body of literature on self-regulation, there are two prominent gaps in research. Firstly, how professionals self-regulate their learning in the context of daily work is not well understood (Siztmann et al, 2005). Most SRL research has taken place in formal, instructional settings such as secondary schools or universities. In these settings, learning itself is the goal, whilst in the workplace learning is a means to an end (doing the work) and a by-product of work (Eraut et al, 2000; Resnick, 1987). In contrast, organisational psychology research has studied self-regulation in the workplace (Locke and Latham, 2002; Vancouver and Day, 2005; Kanfer, Chen and Pritchard, 2008; Lord, Diefendorff, Schmidt, and Hall, 2010), however this body of research is largely focused on the self-regulation of work performance, rather than the self-regulation of learning. One exception is a body of studies from the field of teacher training, which examined self-regulated learning among school and university teachers (eg. Bolhuis, 2000; Bolhuis and Voeten, 2004; van Eekelen et al, 2005; Tillema and Kremer-Hayon, 2002; Nitsche et al, 2011; Randi, 2004). This literature distinguished between three types of self-regulated learning in the workplace: planned learning, spontaneous unplanned learning, and non-linear learning - with unplanned learning arising as a result of an external driver (eg organisational factors) or a problem situation being the most frequently encountered mode (van Eekelen et al, 2005). Whilst these studies have made important theoretical and methodological contributions, they are too specific to the teaching profession and to work in formal educational settings, so the extent to which the findings and measures generated through these studies can help explain self-regulated learning in workplaces other than schools and universities is unclear.

Secondly, research into self-regulation has been typically conducted under laboratory conditions, among disconnected individuals. This has resulted in continued lack of understanding of the impact of the environment -other people or organisational factors - upon individuals' selfregulatory practices. In summary, the extent to which extant research in SRL may generalise to workplace learning settings, where individuals themselves are largely responsible for setting and achieving their own learning goals, where learning is driven by work demands and where complex interdependences among people exist (Eraut, 2004) remains unclear. Sitzmann et al (2011) called for researchers studying self-regulation to "adjust their focus to accommodate how learning occurs in the modern work" (p. 438) and to employ "qualitative research to better understand how selfregulation plays out...in different environments" (p. 436).

The exploratory study reported in this paper is a response to this call. Our aim is to surface the strategies that professionals use to plan and attain their learning goals as part of everyday work and to analyse the factors that impact the formation of their learning goals. We did not examine the affective aspects of self-regulation (feelings) nor did we investigate cognitive processes (thoughts, self-efficacy beliefs) underpinning self-regulatory strategies. Although the cognitive and affective dimensions of self-regulation are as important as the behavioural aspect is, the analysis of the former is beyond the scope of this study. Learning in the workplace is shaped by goal-directed activities individuals engage in, and the nature of the goals themselves. We identify how 
professionals plan, implement and reflect upon their learning goals, analysing similarities and differences between experts, novices and mid-career professionals. We analyse how professionals draw upon available environmental resources, such as other people or organisational processes, to regulate how they plan and attain their learning goals. The study is guided by the following research questions:

1) What factors stimulate formation of learning goals in the workplace?

2) What strategies do professionals use and what other people do they draw upon when planning and attaining their learning goals?

Our focus is on knowledge workers - highly-skilled professionals educated to (post)graduate level, whose work is primarily concerned with knowledge creation through symbolic-analytical activities (Drucker, 1969). The context of the study is a global company in the energy sector. This organisation provides extensive formal learning programmes (courses and workshops designed and delivered in-house) and informal learning opportunities (mentoring and coaching schemes, job rotation, knowledge sharing networks, attendance of seminars and conferences) for both novice and expert employees. Emphasis is placed on employees' personal responsibility for organising their own learning.

In the next sections, we begin by reviewing relevant prior research to provide a context in which to contextualise our results. While a systematic review of the corpus of work in all relevant areas is beyond the purpose of this paper, we use these studies as examples to characterise the state-of-theart. Secondly, we present and discuss the findings from our study. We conclude by outlining implications for practice and proposing directions for future research.

\section{Workplace and self-regulated learning: An overview of previous research}

The work reported in this paper is guided by Zimmerman's three-phase model of self-regulation which has been influential in education (Zimmerman, 2005). Zimmerman's model postulates that self-regulatory processes fall into three cyclical phases: planning of learning goals,

implementation/ attainment of goals, and self-reflection. Each of the phases of self-regulation of learning is comprised of distinct, but interlinked sub-processes. Planning includes goal setting and strategic planning. Implementation is comprised of self-experimentation and self-observation and includes various task-management strategies. Self-reflection incorporates self-evaluation, causal attribution and adaptation of one's strategies.

Unlike the controlled, formal learning settings, in which a significant proportion of SRL research has been conducted to date, real-world workplaces are complex socio-technical systems where multifaceted interdependencies exist between individuals populating these systems (Billett, 2002), between individuals, their work practices and technologies (Szymanski and Whalen, 2011) as well as organisational rules and goals (Engestroem, 2008). A number of key characteristics of workplace learning that could be usefully brought to bear on an analysis of learning goal attainment in the workplace can be derived from the literature. In the remainder of this section, we discuss examples of relevant research from the workplace learning and self-regulated learning domains. Rather than treating these two sets of literatures in isolation, we discuss them in an integrated fashion, structuring our presentation around five key themes: integration of work and learning; impact of organisational factors; learning from and with other people; self-reflection; and similarities and differences in self-regulatory practices of experts and novices. These five themes, while useful in the interpretation of our findings, do not represent a comprehensive synthesis of these two very broad literatures - such a synthesis is beyond the purpose of this paper.

Firstly, a critical important feature of workplace is the close intertwinement between work goals and learning goals (Stenstroem and Tynjala, 2009). This is because in the workplace learning is determined by and integrated with work tasks and priorities (Billett, 2004). For example, Kooken, Ley and Hoog (2007) showed that, while some examples of learning driven purely by curiosity 
could be observed in the workplaces that they had studied, the majority of workplace learning was strongly driven by work tasks. As Randi (2004) argued 'in organisations focused on productivity, work is valued over learning and learning is developed for work's sake" (p. 1833). The work-driven nature of learning in workplace contexts is, therefore, likely to lead to an emphasis on the outcome rather than the process of learning and to self-regulation to be defined in terms of accomplishing specific tasks, such as meeting a sales goal or developing new product. What is the potential implication of this overemphasis on outcome rather than process of learning? SLR literature distinguishes between process and outcome goals, postulating that when individuals adopt process goals, they focus on improvement of their strategy or technique, whereas when adopting outcome goals they aim to enhance their performance (Zimmerman, 2006). It has been shown that focusing on outcome goals alone can be detrimental to improvement of one's skill (Zimmerman and Kitsantas, 1996) and that those individuals who set both process and outcome goals perform better than those who set singular goals (Filby et al, 1999). Given that learning in the workplace is a byproduct of work rather than a goal in itself, it can be hypothesised that learning goals in the workplace are likely to be predominantly outcome-focused rather than process-focused, possibly leading to detrimental effects on learning. However, research on the impact of different types of goals on learning has been conducted largely in the context of the development of motoric skills in sports (athletics, cycling), and the extent to which they may generalise to workplace learning contexts remains unclear.

A second key point is the crucial role that broader organisational factors play in workplace learning generally, and in goal formation more specifically (Felstead, Fuller, Jewson, and Unwin, 2009; Rainbird, Fuller, and Munro, 2004). Variations in the extent and nature of support that workplaces provide for learning have been highlighted in the literature, most notably by Fuller and Unwin (2004) who conceptualised a continuum of expansive-restrictive learning environments. Specific jobs and even sectors differ in their affordances for learning, a feature captured in the notion of 'learning-intensive job' (Skule, 2004). Similarly, work environments differ in the extent of selfregulation that they afford. For example, Randy (2004) argued that workers' self-regulation is enabled and facilitated when the workplace environment affords opportunities for problem solving and learning in the context of everyday work; when workers are offered choice in how they learn; when they have opportunities to articulate and share their knowledge; and when the workplace presents both challenge and support, scaffolding workers to higher levels of performance. Educational psychology research suggested that goal structures inherent in a classroom environment could affect motivation, cognitive engagement and achievement within the environment (Eren, 2009). This research highlighted that in classroom settings teachers can create different goal structures for learners by using specific instructional, evaluation and learner grouping strategies. Whether similar effects on learning goal formation in the workplace exist, for example through job design, performance review systems, and team formation strategies, is unclear, but plausible.

A third central feature of workplace learning is the importance of learning with and from other people (Eraut, 2007; Koopmans, Doornbos, \& van Eekelen, 2006; Tynjala, 2008). Collaboration with and guidance by 'significant others' (more knowledgeable colleagues, mentors, clients) are important stimuli for individuals in setting and achieving their learning goals in the workplace (Lave, 1991). Collin and Paloniemi (2008) highlighted the importance of informal and incidental opportunities for learning with and from others in organisations. Pazy (2004) showed a correlation between the social environment and self-regulatory learning behaviour at work. Meanwhile, SRL literature has largely focused on individual learning, although socio-cognitive theories of SRL acknowledge the role of social factors in the individual's learning processes (Zimmerman, 2005). In recent years, concepts such as co-regulation, shared regulation and social regulation have been advanced to account for the social dimensions of SRL (eg. Volet et al, 2009). However, this strand of work has been limited to formal, classroom learning settings.

Fourth, literature emphasised the crucial role of self-refection in learning and development of expertise. Human activity, including the activity of work, in itself is insufficient for learning to occur. 
The learning value of an activity is in the extent to which the activity incorporates sense-making mechanisms, such as self-reflection (Dewey, 1966). This means that for learning to occur from work, sense-making mechanisms such as reflection must be present in work activity or these may be purposefully designed into work (either by individuals themselves or by organisations). Schoen (1987) has argued that reflection is a crucial element of reflective practice. Socio-cultural theories conceptualised self-reflection as a fundamentally social process, in which self-reflection arises as a response to the presence of an other (Gillespie, 2007).

Finally, previous research has demonstrated a number of similarities and differences in selfregulatory processes of experts and novices. First, while experts tend to set specific process goals, novices often do not set goals at all (Kitsantas and Zimmerman, 2002). Second, when selfevaluating their goal attainment, experts tend to set standards that are neither too high nor too low, whilst novices have difficulty in formulating goals of an appropriate level of difficulty (Locke and Latham, 2002). Third, experts are more systematic, selective and adaptive in their reflection upon their learning and their self-monitoring of their use of self-regulatory strategies than novices are (Kitsantas et al, 2002). Fourth, experts are better than novices - more selective, adaptive and selfinitiated- in seeking help by drawing upon 'significant others' to assist them in learning (Karabenek, 1998). This strand of research has generated important insights, however it too has largely focused on learning in academic or physical training contexts, leading to a difficulty in ascertaining the extent to which these findings may help explain self-regulation in workplace learning.

\section{Methods}

The study described in this paper was part of a larger research project aimed at investigating how professionals learn in the context of daily work (Margaryan, Milligan, and Littlejohn, 2009). The larger study employed a mixed-methods research approach (Johnson and Onwuegbuzie, 2004), including a quantitative phase (questionnaire survey, $\mathrm{n}=469$ ) followed by a qualitative phase (semi-structured interview, $\mathrm{n}=29$ ). In this paper, we report on the findings of the qualitative phase only. We do not report the survey results, because the survey was focused on other aspects of workplace learning only indirectly related to the topic of this paper. We draw on the survey solely to identify the experience level of the respondents and the country in which they worked at the time of the interviews.

\subsection{Data collection procedure and instrument and data analysis method}

Semi-structured interviews lasting one hour on average were conducted with a group of knowledge workers from a multinational energy company. Interview respondents were recruited through the above-mentioned survey, at the end of which the respondents where asked to volunteer for followup interviews. Twenty-nine respondents volunteered to be interviewed. The interviews took place in November 2008-March 2009.

Interviews were by telephone. At the start of the interview, the respondents were asked to think about their most significant learning experience in the past year - the project or task from which they had learned the most. The interview questions were designed to elicit data about the ways in which professionals set and attain their learning and development goals to complete the project/task. In addition, interviewees were asked to describe their job role, typical tasks they performed, the extent of autonomy versus interdependency and collaboration inherent in their job, team structures they operated within, in particular team size and formality. The interview script is at http://dl.dropbox.com/u/6017514/interviewscript.pdf

Interview data were analysed using a combination of pre-defined and emergent codes related to the three key areas of focus reflected in the research questions. The three areas of focus included: 1) factors stimulating formation of learning goals; 2) strategies of goal planning and attainment; 
and 3) other people the respondents drew upon when planning and attaining their goals. Firstly, the entire dataset was coded using these three broad areas. Secondly, the data within each of these three areas were further analysed thematically, using emergent codes. For instance, the emergent codes included those related to different types of factors, different types of strategies and different types of people that were described by the participants. Thirdly, the respondents were categorised into three groups according to their experience level (novice, midcareer and experienced), and the identified factors stimulating formation of learning goals, goal planning and attainment strategies and types of people respondents drew upon were compared and contrasted across these three groups. In all three phases of the analysis, coding for a sample of data was cross-checked by three researchers to ensure reliability and consistency.

\subsection{Respondents}

Interview respondents ( $\mathrm{n}=29$ ) included engineers; scientists (geophysicist, geologists); HR, knowledge management and procurement specialists; and instructional designers. The respondents were distributed in 12 countries, including Netherlands (13/29), US (3/29), UK (3/29), Canada (2/29), and one participant each from Russia, Portugal, Greece, Brazil, Egypt, Germany, India, and Brunei.

Of 29 interview respondents, 10 were novices (N), 12 were experts (E) and 7 were mid-career professionals (MC). We defined as experts those who had 11 and more years of experience and novices as those who had up to 3 years of experience in their discipline at the time of the interview. Those who had 4-10 years of experience were defined as mid-career professionals. We acknowledge the problematic nature of grouping experts and novices in this way, as this method considers merely the quantitative rather than the qualitative nature of experience. Obtaining objective measures of expertise level, for example performance appraisal information or peer assessment, was unfeasible in this study. To mitigate, we triangulated the data on the years of experience in their specialism with the number of years they had spent with the company and their time in their current role. We then compared these data with respondents' perceptions of their status as experts, all identified through the pre-interview survey.

\subsection{Sample representativeness}

The interview sample $(n=29)$ has representation from a range of geographic locations and disciplines, and different job profiles and experience levels. However, the exploratory nature of this study meant that the sample was small and, therefore, unrepresentative. Furthermore, the fact that the respondents were selected on the basis of their interest in the study may have introduced a sampling bias. Driven by pragmatic consideration inevitable when conducting research in realworld business contexts, this sampling strategy did not account for the number of potential participants who may have been omitted from the study. These limitations are common in qualitative research (Daly and Lumley, 2002). Therefore, the data presented in this paper can only be considered a snapshot of employees' views and may not be representative of the entire worker population of this company. Foregoing these methodological weaknesses, the study offers a valuable contribution to empirical research in the field.

\section{Results and discussion}

\subsection{What factors stimulate learning goals in the workplace?}

Our data suggests that SRL in the workplace is structured by and deeply integrated with work tasks and priorities. Interviews revealed a prevalence of outcome rather than process goals, in line with the performance-oriented nature of workplace learning, as highlighted in the discussion of the previous research. In this study we did not examine the correlation between the type of goals and 
learning outcomes, so whether or not the focus on outcome goals was detrimental to learning is unclear.

For the predominant majority of respondents learning goals were driven by organisational factors, mainly by work tasks or job role requirements. Subsequently, learning goals were usually structured around short- and long-term organisational needs arising from these tasks and job role requirements. When asked whether learning goal planning was integrated with work tasks, only one out of 29 respondents (a novice Procurement Analyst) said she was motivated by desire to acquire more general knowledge not directly tied to a work task - possibly because her job was not sufficiently learning-intensive (Skule, 2004):

"There is not a lot I need to learn to function properly in my job, but a lot of things I would like to just for my own knowledge and my own appreciation. ...Most of the things I want to explore aren't specific to what I am doing in day-to-day activities" (N4).

Data from the rest of the respondents indicates that their learning plans were tightly integrated with their work tasks. In van Ekelen et al (2005) terms, their learning appears to be largely externally regulated.

However, clearly delineating and decoupling internal factors (that is, factors pertaining solely to an individual) from external factors (that is, factors pertaining solely to the environment) is not straightforward. Socio-cognitive theories of SRL suggest (Zimmerman, 2005) that social, environmental and individual self-influences are interdependent. Therefore learning cannot be solely internally- or externally-regulated. This is particularly relevant in workplace contexts, where learning is highly interactional and is a by-product of work rather than a goal in itself (Eraut, 2004).

The synthesis of data highlighted two key factors stimulating the formation of learning goals in the workplace: task and role requirements and individual developmental needs related to career progression. These factors can be distinguished in terms of a temporal perspective, current task and role requirements representing a short-term perspective and individual development needs reflecting a longer-term orientation. The short-term perspective was reflected equally in the data from experts, novices and mid-career professionals, with no observable differences between these three groups. In contrast, the long-term perspective was reflected predominantly in novices' responses.

\subsection{How do professionals regulate their learning?}

Respondents indicated that their learning was highly iterative. The ever-increasing complexity of problems and projects ("we are stepping further and further beyond everyone's comfort zone" (MC3)) meant that it was impossible for any individual to learn everything one needed to know to solve difficult problems. Our analysis suggests that SRL in the workplace, unlike in educational or laboratory contexts, is difficult to clearly delineate into discrete phases of planning, implementation and reflection. The phases postulated by phase-theories of SRL, therefore, may not be analytically meaningful in workplace contexts, where tasks and goals are much less bounded or well-defined. In the workplace learning contexts, discrete phases may be meaningful only when dealing with very specific, clearly defined, small-scale tasks and goals that can be more easily delineated:

"For my job, learning is more continuous. Not all jobs are like that. For instance, the Technicians, they are more the former way you described: you learn how to do a technique and then you master this technique and you go on. Mine is definitely continuous, especially in today's field, where the traditional curricular disciplines are becoming much more frayed. There is increasing [interdisciplinary] overlap, especially when you need to innovate, when you have to push the boundaries of existing technology... So mine is definitely continuous." (N2) 
The analysis highlighted a key mechanism for support of SRL: Individual Development Planning (IDP), a process closely linked with annual performance appraisal. These two organisational processes together support individuals in annual planning of work goals and tasks, identification of learning needs and formulation of learning goals to help them achieve their short-term work goals and long-term career aspirations, in consultation with their line managers. IDP results in concrete actions for addressing the learning goals, for example it could include attendance of specific courses; coaching and mentoring; or conference attendance. Respondents across all levels of expertise discussed IDP as a central strategy that they used. However, there were differences in the perceptions of the usefulness of IDP. Specifically, experts viewed IDP as more relevant for novices than for experienced professionals. Some experts viewed IDP as a tool for planning formal learning (courses) and therefore, in their view, not relevant to experts, who, in their view, tended to prefer experiential, non-formal learning.

Whilst IDP, together with the annual performance appraisal, is central to learning goal planning, it also provides a structured set of formal or informal reflection points throughout a year:

"I have my personal goals and on a regular basis they are discussed with my line manager. Now, periodically he will remind me, or actually I will remind him, that we need to update my goals. We have a rolling annual process around individual development plans and targets, so it is very well structured, in my opinion. It is very open and also it is very, kind of, led by the individual. And it links into the team goals obviously, but also there is personal elements in there as well." (E10)

Other strategies that emerged from the data included use of competency assessment and performance feedback mechanisms (eg '360 degree feedback' whereby individuals seek feedback on their work from their supervisors, as well as peers and supervisees) available within the organisation. However, these strategies were mentioned much less frequently than IDP - only three respondents, including two experts and a novice, mentioned them.

The analysis surfaced two additional organisational factors, which appear to play an important role in goal planning. Firstly, individual's perceptions regarding career development possibilities in their organisation, exemplified in a quote from a mid-career Procurement specialist:
"At the moment, I don't know about my future development plans or next position that I can work in. So I don't know for what I should prepare. When you know that you are going to use this or that functionality in future, let's say half a year or in one month, you will start to prepare for it, you will start to acquire some knowledge about this particular function. But when you do not know what is going to be your assignment in the next year, you don't know what to do." (MC1)

Secondly, individual's perception of how the organisation views their career progression potential, in particular based on what line managers communicate to employees about organisational intentions:

"I don't know how to plan, because it is rather difficult to say if there is an opportunity for you to go further or not. You don't know the plans of your bosses, whether they can see for you to be good for some supervisory position or not. Even if they do, they do not share this knowledge with you. So you do not know what you should be prepared for. You do not plan your career like in the case that, okay they say 'we are looking at you as a Supervisor for his or that department in the near future, please get prepared'." (MC1)

Overall, our enquiry highlighted the significance of organisational processes as key factors impacting SRL in the workplace. This is not surprising given the prevalent role of the organisational factors stimulating the formulation of learning goals in the workplace. When probed on reasons underpinning the significance of these, many respondents indicated that they found organisational mechanisms sufficient and therefore did not seek or use additional, personal approaches. Existing organisational processes and mechanisms appear to serve as reference points for self-regulated 
learning in the workplace.

The interviews also revealed that while planning and attaining learning goals, professionals often draw upon others. When faced with a new problem or a new task for which they need to gain knowledge quickly, most respondents, whether novice or expert, tended to draw heavily upon their personal networks of trusted colleagues to diagnose their learning needs and attain their learning goals. Respondents discussed three key categories of workplace 'significant others': line managers, mentors/coaches, and colleagues in the organisation (other than those in the immediate team the person is working within). From these three categories, line managers were mentioned most frequently. Line managers were discussed more frequently by novices and experts than by midcareer respondents. Line managers' central role in workplace learning and learning goal formation is well established in the literature (Broad, 1997; Locke et al, 1988; Margaryan, Milligan, and Littlejohn (in press); Senge, 1990;). Mentors appear to play a role similar to that of the line managers, chiefly providing advice on skills assessment and learning needs and helping employees identify formal and informal learning opportunities to address the needs. Our findings suggest that mentors are more peripheral to the planning process than line managers are. This may be because the goal planning processes in this organisation are heavily structured around IDP, and mentors, unlike line managers, do not participate in the approval of the individual development plan, although they may contribute in the ways outlined above. In addition, not everyone in this organisation and in our sample had a mentor. Finally, colleagues were the third key category that emerged from the data. Previous research showed that in the workplace peers influence individual's goal setting through social pressure, conveyance of normative information, acting as role models or generating competition (Earley and Kanfer, 1985). Mentors and colleagues were mentioned more frequently by novices than experts or mid-career professionals.

It was difficult to distinguish between respondents' reflections on learning tasks and their reflections on work tasks, even though the interviewers systematically probed for learning and development-specific reflections. This is likely to be due to the close interweaving of work and learning (Eraut, 2004). A number of key themes were identified. Firstly, reflection practices are structured around work projects. A typical example is outlined by an expert:

"When I was in <project name>, we always had a look-back session. After the project was over and the last tally was totalled, we would go and sit in a room together with peers. We had a look-back [at] what went right on the project, what went wrong, what not to repeat. And we put all that in a database... to capture those learnings [sic] so others can learn from the." (E2)

Secondly, our analysis revealed lack of explicit focus on reflection on learning in the workplace across all experience levels within the sample. The majority of respondents, novices and experts alike, appear seldom to engage in deliberate and systematic self-reflection. In the workplace, learning is driven by task and performance demands, therefore there are limited opportunities for systematic self-reflection. Where the opportunity for deliberate reflection exists, such as in project after-action reviews, these are closely linked to the immediate work task, rather than being focused on learning per se. Most interviewees could not explicate any specific reflection strategies that they may have used. Overall, respondents appeared to focus on acting rather than reflecting, with lack of time and lack of reflection skills indicated as the two key reasons:

"The whole culture is very heavily project-oriented, so there are deadlines, there are demands from clients and there are PowerPoints to be made and presentations to be given. So even though I say that working is very important I feel that we need time to sit back and reflect on what we are actually doing and what we are learning..." (MC5)

"I am not much of a reflector, which is a skill I need to learn. When I have had the time, I look back on what was good and what I could do better at." (N8)

This finding is in line with results discussed in teacher training research, which also identified lack of planned and structured reflection amongst teachers (Van Eekelen et al, 2005) suggesting that 
professionals in the workplace may need dedicated and sustained opportunities to reflect on their learning in the context of work.

\section{Conclusions, implications, limitations and future research}

This small-scale study indicates that self-regulated learning in the workplace is structured by and deeply integrated with work tasks. Learning goals are largely driven by organisational factors, in particular short-term work tasks as well as individuals' longer-term development needs. In addition, the formation of learning goals is constrained by individuals' perceptions of career development potential in the organisation in which they work, as well as by their perception of how the organisation views their career progression potential, in particular how the organisation communicates its intentions to workers. The analysis also contributes evidence that self-regulated learning in the workplace is highly social, with individuals drawing upon line managers, mentors and colleagues extensively when planning and attaining their learning goals. Furthermore, the study identified that SRL in the workplace is iterative, fluid and continuous rather than clearly delineated into discrete stages of planning, implementation and reflection, as postulated by extant SRL theories. Finally, the interviews highlighted a paucity of deliberate, systematic self-reflection on learning, due to predominantly outcome-oriented rather than process-oriented nature of learning in the workplace, as well as lack of knowledge of reflection strategies and techniques on the part of the workers.

Whilst our sample $(n=29)$ is too small to discern robust patterns, some differences in SRL in novices, experts and mid-career professionals have been identified. In particular, while short-term focus on task and role requirements as determinants of learning goal formation was distributed equally between the three groups, the long-term developmental focus was more characteristic of novices rather than experts or mid-career workers. Furthermore, line managers appear to be more central in novices' and experts' accounts of learning rather than mid-career professionals' practices. In contrast, mentors and colleagues were mentioned more frequently by novices than experts or mid-career professionals. These differences, however, are indicative: they have not been tested for significance because our sample was small.

A key limitation of our study is the small sample size and the limited data collection methodology using retrospective, self-reported measures. Workplace learning is difficult to study because it tends to be invisible, not only to researchers but often to the individuals themselves. Selfregulatory processes are often not readily accessible at a conscious level. While our chosen methodology was appropriate for the overarching research goals (examination of individuals' perceptions of learning strategies and practices), we acknowledge the problems associated with the use of interviews. In particular, previous research has suggested that individuals' judgements of their learning may be inaccurate (Townsend and Heit, 2011) and that individuals may have limited or no direct introspective access to higher-order cognitive processes (Nisbett and Wilson, 1977). Therefore, future research in this area should move beyond retrospective, self-reported data towards methods that allow more objective, real-time elicitation of strategies and practices that individuals use to regulate their learning in the workplace. Using more in-depth ethnographic methods, including a larger group of participants and multiple data sources that could be triangulated, would help to generate more holistic data, identify more robust patterns and surface more nuanced learning processes. However, such methodologically sophisticated studies are also difficult to get support (and funding) for, because they normally require significant time and resource investment that companies/funders are not always prepared to make. Finally, to advance the theorising of self-regulated learning in the workplace, future research should break free from interdisciplinary boundaries, by bringing together the workplace learning, educational psychology and organisational psychology literatures, which have been developing in parallel, but which can usefully learn from each other. 
Although more research would be required to ascertain and systematise generalities related to selfregulatory practices in the professional workplace, the present study could nevertheless inform the design and facilitation of learning provision in organisations. Three key specific recommendations for practice are proposed. Firstly, a key point arising from the study is the lack of deliberate reflection on learning in the workplace. Self-reflection is crucial to successful learning, and workers may need dedicated and sustained opportunities to reflect on their learning in the context of work. The findings of this study suggest that work projects could be a useful opportunity for reflection on learning. Extant project review mechanisms such as 'after-action reviews' (AARs) or mid-project reviews could be used for structured reflection about each individual's personal learning, in terms of his or her development of new knowledge, skills and behaviours, rather than focusing only on individual or team performance on the project. Such structured reflection processes should be designed so as to encourage constructive self-evaluation and actionable improvement, helping individuals analyse on how they had done in relation to their learning goals, what they had learnt, what they still have to learn and what they would do differently in the future. Secondly, our findings suggest that professionals, specifically novices, may not always know how to self-reflect in a way that is conducive to learning. Organisations, therefore, should consider supporting individuals in the development of their reflection skills, for example through provision of training or self-study materials on reflection strategies and tools that workers can use to analyse their own learning and development or through informal learning opportunities such as mentoring, coaching or individual development planning discussions with supervisors. Finally, given that individuals' perceptions of career development opportunities within their organisations, in particular individuals' knowledge of how the organisation views their career progression potential, appear to be an important factors affecting how professionals set their learning goals, organisations may want to ensure that supervisors periodically discuss the career development opportunities with the workers.

\section{Acknowledgements}

The authors would like to thank Dr Karen Smith (University of Greenwich, UK, previously at Glasgow Caledonian University, UK) and Mr. Dane Lukic (Glasgow Caledonian University) for their valuable help in the collection and coding of the interview data. We are grateful to the participants of this study and our company research partners for their time, insights and stimulating collaboration.

\section{References}

Austin, J. T., \& Vancouver, J. B. (1996). Goal constructs in psychology: Structure, process, and content. Psychological Bulletin, 120(3), 338-375.

Bateman, T., \& Barry, B. (2012). Masters of the long haul: Pursuing long-term work goals. Journal of Oragnizational Behavor, 33(7), 984-1006.

Billett, S. (2010) (Ed.). Learning through practice: Models, traditions, orientations, and approaches. Dordrecht: Springer.

Billett, S. (2004). Learning through work: Workplace participatory practices. In Rainbird, H., Fuller, A., \& Munro, A. (Eds.), Workplace learning in context (pp. 109-125). London: Routledge.

Billett, S. (2002). Toward a workplace pedagogy: Guidance, participation, and engagement. Adult Education Quarterly, 53(1), 27-43.

Billett, S., Harteis, C., \& Etelaepelto, C. (Eds.) (2008). Emerging perspectives of workplace learning. Rotterdam/Taipei: Sense Publishers.

Bolhuis, S. (2000), Naar zelfstandig leren: Wat doen en denken docenten? [Towards self-regulated learning: What do teachers do and think?]. Leuven/Apeldoorn: Garant. 
Bolhuis, S., \& Voeten, M. (2004). Teachers' conceptions of student learning and own learning. Teachers and Teaching: Theory and Practice, 10, 77-98.

Broad, M. (1997). Transferring learning to the workplace. Alexandria, VA, USA: ASTD.

Carver, C., \& Scheier, M. (2005). On the structure of behavioural self-regulation. In Boekaerts, M., Pintrich, P., and Zeidner, M., (Eds.), Handbook of self-regulation (pp. 41-84). San Diego, CA, USA: Academic Press.

Cheetham, G., \& Chivers, G. (2001). How professionals learn in practice: An investigation of informal learning amongst people working in professions. Journal of European Industrial Training, 25(5), 248-292.

Colley, H., Hodkinson, P., \& Malcolm, J. (2002). Non-formal learning: Mapping the conceptual terrain, a consultation report. Leeds: University of Leeds. Retrieved on November 9, 2012 from http://www.infed.org/archives/e-texts/colley informal learning.htm

Collin, K., \& Paloniemi, S. (2008). Supporting experience sharing as participatory workplace practice. In Billett, S., Harteis, C. and Etelaepelto, C. (Eds.), (2008) Emerging perspectives of workplace learning (pp. 167-181). Rotterdam/Taipei: Sense Publishers.

Collin, K., van der Heijden, B., \& Lewis, P. (2012). Continuing professional development. International Journal of Training and Development, 16(3), 155-163.

Daly, J., \& Lumley, J. (2002). Bias in qualitative research designs. Australian and New Zealand Journal of Public Health, 26(4), 299-300.

Dewey, J. (1966). How we think. New York: Free Press.

Drucker, P. (1969). The age of discontinuity. New York: Harper and Row.

Earley, P. C., \& Kanfer, R. (1985). The influence of component participation and role models on goal acceptance, goal satisfaction and performance. Organizational Behavior and Human Decision Processes,36, 378-398.

van Eekelen, I., Boshuizen, H., \& Vermunt, J. (2005). Self-regulation in higher education teacher learning. Higher Education, 50, 447-471.

Engestroem, Y. (2008), From teams to knots: Studies of collaboration and learning at work. New York: Cambridge University Press,

Eraut, M. (2007). Learning from other people in the workplace. Oxford Review of Education, 33(4), 403-422.

Eraut, M. (2004). Informal learning in the workplace. Studies in Continuous Education, 26(2), 247273.

Eraut, M., Alderton, J., Cole, G., \& Senker, P. (2000). Development of knowledge and skills at work. In Coffield, F. (Ed.), Differing visions of a learning society, Vol.1 (pp. 231-262). Bristol: The Policy Press.

Eren, A. (2009). Exploring the relationships among mirror neurons, theory of mind, and achievement goals: Towards a model of achievement goal contagion in educational settings. Educational Research Review, 4, 233-247.

Ericsson, A. (2006). The influence of experience and deliberate practice on the development of superior expert performance. In Ericsson, A., Charness, N., Feltovich, P., \& Hoffman, R. (Eds.), The Cambridge handbook of expertise and expert performance (pp. 683-703). New York: Cambridge University Press.

Felstead, A., Fuller, A., Jewson, N., \& Unwin, L. (2009). Improving working as learning. London: Routledge. 
Filby, W., Maynard, I., \& Graydon, J. (1999). The effect of multiple goal strategies on performance outcomes in training and competition. Journal of Applied Sports Psychology, 11, 230-246.

Gijbels, D., Raemdonck, I., Vervecken, D., \& van Herck, J. (2012). Understanding work-related learning: the case of ICT workers. Journal of Workplace Learning, 24(6), 416 - 429.

Gillespie, A. (2007). The social basis of self-reflection. In Valsiner, J., \& Rosa, A. (Eds.), The Cambridge handbook of sociocultural psychology (pp. 678-691). New York: Cambridge University Press.

Hadwin, A., Webster, E., Helm, S., McCardle, L., \& Miller, M. (2011). Exploring patterns of task specific goal setting and motivation regulation. In Proceedings of the 2011 Conference of the European Association for Research in Learning and Instruction (pp. 35-36). Exeter, UK: University of Exeter.

Johnson, R. B., \& Onwuegbuzie, A.J. (2004). Mixed methods research: A research paradigm whose time has come. Educational Researcher, 33(7), 14-26.

Kanfer, R., Chen, G., \& Pritchard, R. (2008) (Eds). Work motivation: Past, present and future. New York/London: Routledge.

Karabenek, S. (1998). Strategic help-seeking: Implications for learning and teaching. Mahwah, USA: Lawrence Erlbaum Associates.

Kitsantas, A., \& Zimmerman, B. (2002). Comparing self-regulatory processes among novice, nonexpert and expert volleyball players: A microanalytic study. Journal of Applied Sport Psychology, 14, 91-105.

Kooken, J., Ley, T., \& de Hoog, R. (2007). How do people learn at the workplace? Investigating four workplace learning assumptions. Creating New Learning Experiences on a Global Scale, 158-171.

Koopmans, H., Doornbos, A., \& van Eekelen, I. (2006). Learning in interactive work situations: It takes two to tango; why not invite both partners to dance?. Human Resource Development Quarterly, 17(2), 135-158.

Lave, J. (1991). Situated learning in communities of practice. In Resnick, L., Levine, J., \& Teasley, S. (Eds.), Perspectives on socially shared cognition (pp. 63-82). Washington, DC, USA: APA.

Littlejohn, A., Milligan, C., \& Margaryan, A. (2012). Charting collective knowledge: Supporting selfregulated learning in the workplace. Journal of Workplace Learning, 24(3), 226 - 238.

Locke, E., \& Latham, G. (2002). Building a practically useful theory of goal setting and task motivation: A 35-year odyssey. American Psychologist, 57, 705-717.

Locke, E. A., Latham, G. P., \& Erez, M. (1988). The determinants of goal commitment. Academy of Management Review, 13, 23-39.

Lord, R. G., Diefendorff, J. M., Schmidt, A. M., \& Hall, R. J. (2010). Self-regulation at work. Annual Review of Psychology, 61, 543-568.

Margaryan, A. (2008). Work-based learning: A blend of pedagogy and technology. Saarbrücken: Akademikerverlag.

Margaryan, A., Milligan, C., \& Littlehohn, A. (in press). Managers as workplace learning facilitators. International Journal of Human Resource Development and Management.

Margaryan, A., Milligan, C., \& Littlejohn, A. (2009). Self-regulated learning and knowledge sharing in the workplace: Differences and similarities between experts and novices. In Proceedings of the 2009 Researching Work and Learning (RWL) Conference. Roskilde, Denmark: University of Roskilde.

Nisbett, R., \& Wilson, T. (1977). Telling more than we can know: Verbal reports on mental processes. Psychological Review, 84(3), 231-259. 
Nitsche, S., Dickhäuser, O., Fasching, M., \& Dresel, M. (2011). Rethinking teachers' goal orientations: Conceptual and methodological enhancements. Learning and Instruction, 21(4), 574-586.

Pazy, A. (2004). Updating in response to the experience of lacking knowledge. Applied Psychology, 53(3), 436-452.

Pintrich, P. (2000). The role of goal orientation in in self-regulated learning. In Boekaerts, M., Pintrich, P., \& Zeidner, M., (Eds.), Handbook of self-regulation (pp. 451-502). San Diego, CA, USA: Academic Press.

Rainbird, H., Fuller, A., \& Munro, A. (2004) (Eds.). Workplace learning in context. London: Routledge.

Randi, J. (2004). Teachers as self-regulated learners. Teachers College Record [online] http://www.tcrecord.org/Content.asp?ContentID=11672

Resnick, L. (1987). The 1987 presidential address: Learning in school and out. Educational Researcher, 16(9), 13-20.

Schoen, D. (1987). Educating the reflective practitioner. San Francisco: Oxford.

Skule, S. (2004). Learning conditions at work: A framework to understand and assess informal learning in the workplace. International Journal of Training and Development, 8(1), 8-20.

Senge, P. (1990). The leader's new work: Building learning organisations. Sloan Management Review, 32 (1), 7-23.

Sitzmann, T., \& Ely, K. (2011). A meta-analysis of self-regulated learning in work-related training and educational attainment: What we know and where we need to go. Psychological Bulletin, 137(3), 421-442.

Stenstroem, M.-L., \& Tynjala, P. (2009) (Eds.). Towards integration of work and learning: Strategies for connectivity and transformation. Amsterdam: Springer.

Szymanski, M., \& Whalen, J. (2011) (Eds.), Making work visible: Ethnographically grounded case studies of work practice. New York: Cambridge University Press.

Tillema, H., \& Kremer-Hayon, L. (2002). Practice what we preach: Teacher educators' dilemmas in promoting self-regulated learning. Teacher and Teacher Education, 18, 593-607.

Townsend, C., \& Heit, E. (2011). Judgements of learning and improvement. Memory \& Cognition, 39(2), 204-216.

Tynjälä, P. (2008). Perspective into learning in the workplace. Educational Research Review, 3, 130154.

Vancouver, J.B., \& Day, D.V. (2005). Industrial and organisational research on self-regulation: From constructs to applications. Applied Psychology: International Review, 54, 155-185.

Volet, S., Summers, M., \& Thurman, J. (2009). High-level co-regulation in collaborative learning: How does it emerge and how is it sustained? Learning and Instruction, 19(2), 128-143.

Zimmerman, B. (2005). Attaining self-regulation: A social cognitive perspective. In Boekaerts, M., Pintrich, P., \& Zeidner, M., (Eds.), Handbook of self-regulation (pp. 13-39). San Diego, CA, USA: Academic Press.

Zimmerman, B. (2006). Development and adaptation of expertise: The role of self-regulatory processes and beliefs. In Ericsson, A., Charness, N., Feltovich, P., \& Hoffman, R. (Eds.), The Cambridge handbook of expertise and expert performance (pp. 705-722). New York: Cambridge University Press.

Zimmerman, B., \& Kitsantas, A. (1996). Self-regulated learning of a motoric skill: The role of goal setting and self-monitoring. Journal of Applied Sport Psychology, 8, 69-84. 